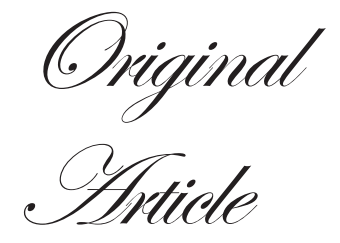

Departments of Pediatrics, ${ }^{1}$ and Radiology ${ }^{2}$

Burdwan Medical College,

West Bengal, India

Department of Pediatrics, ${ }^{3}$

Chittaranjan Seba Sadanand

Sishu Sadan Hospital,

West Bengal, India

Correspondence:

Dr. Tarak Nath Ghosh

Email: tnghosh39@gmail.com

\section{Assessment of normal portal vein diameter in children}

\author{
TarakNath Ghosh, ${ }^{1}$ Mukut Banerjee, ${ }^{1}$ Samit Basu, ${ }^{1}$ Rajib Das, ${ }^{1}$ \\ Prashanth Kumar, ${ }^{1}$ Sangita De, ${ }^{1}$ Mrinal Kanti Ghosh, ${ }^{2}$ Sutapa Ganguly ${ }^{3}$
}

\section{ABSTRACT}

Background and aim: The internal diameter of the portal vein varies with age and anthropometric parameters. The caliber of the normal portal vein in adults has been extensively studied but little is known about portal vein dimensions in the growing child. This study was conducted to establish standards of portal vein diameter by ultrasonography in healthy Indian children based on age, gender and anthropometric parameters.

Methods: Total 306 healthy children between the age of $<1$ month and 12 years, visiting our outpatient departmentor accompanying their siblings were enrolled in the study. The children were distributed into ten age-groups. Each group was further divided in two sub-groups based on gender. Anthropometric parameters including weight, height and chest circumference were measured.Portal vein diameter was assessed by ultrasonography.

Results: The portal vein diameter increases with age, height, weight and chestcircumference. But the values are similar in boys and girls. Multiple logistic regression (adjusted Rsquare:0.922) revealed age ( $\mathrm{p}=0.002)$, height/length $(\mathrm{p}<0.0001)$, weight $(\mathrm{p}=0.011)$, and chest circumference $(\mathrm{p}<0.0001)$, as independent determinants of portal vein diameter. However, height/length emerged as the most consistent determinant (coefficient of regression: 1.536; $\mathrm{p}<0.001 ; 95 \%$ confidence interval: 0.066 - 0.092).

Conclusion: Our results provide a normal range of portal vein diameter according to age, gender and anthropometric parameters. We conclude that portal vein diameter strongly correlates with age and anthropometric variables like height, weight and chestcircumference, with height being the strongest determinant.

KEYWORDS: Portal vein, age, sex, weight, height, chest-circumference

\title{
Introduction
}

Most principles of clinical practice have specific demarcations between the normal and abnormal. In the absence of such standards it is difficult to take definite clinical decisions.In growing children anthropometric parameters like head circumference, chest circumference, height, weight, etc., vary with age. Likewise, the size of internal organs also increases with age. Besides age, gender, ethnic and geographic factors also influence the size of internal organs. The portal vein delivers blood from the intestinal capillaries and spleen to the hepatic sinusoids. ${ }^{1}$ It is easily located at the porta hepatis by gray scale ultrasound ${ }^{2}$ which is a useful tool for monitoringmajor vessels of the portal venous system. ${ }^{3}$

The major abnormality of the portal venous system is portal hypertension. It develops either due to increased resistance or 
increased volume of portal blood flow., ${ }^{3,4}$ This results in enlargement of extrahepatic and intrahepatic portal vessels and the development of spontaneous portosystemic collaterals. ${ }^{4}$ Portal venograms, splenoportography and arteriography have been in use for evaluation of patients suspected of having portal vein thrombosis and portal hypertension. ${ }^{5}$ These methods though accurate, entail risks, discomfort, are time consuming and expensive. ${ }^{2}$ They can result in significant morbidity inpatients with abnormal coagulation and other medical illnesses. ${ }^{6}$ In contrast, ultrasound is well-suited because it is a simple, non-invasive and rapid tool..$^{2,37-9}$ The duplex ultrasound has further facilitated the study of portal venous anatomy and blood flow. ${ }^{3,10}$ The study of portal vein is also useful in diagnosis of many other medical conditions. The caliber of thenormal portal vein in adults has been well studied, ${ }^{6,7}$ but little is known about it ingrowing children at different ages.

We conducted this study to establish the standards of portal vein diameter by ultrasonography in healthy Indian children based on their age, gender and anthropometric parameters.

\section{Methods}

This cross-sectional study was carried out between May 2011 and April 2012 atour Department of Pediatrics.A total 306 children between the ages of $<1$ month and 12 years, who visited our outpatient department or the Well Baby Clinic, as patients or accompanied their siblings, were enrolled in this study. The children were allocated into ten age groups: $<1$ month, 1-3months, 3-6months, 6-12months, 1-2years, 2-4years, 46years, 6-8years, 8-10years, 10-12years. Each group was further subdivided based on gender. Children with history of hepatobiliary disease, cardiac disorders, splenomegaly and portal hypertension were excluded. Children with any history of antenatal, natal or postnatal illnesses were also excluded. While 330 children were eligible for the study as per the inclusion and exclusion criteria, but only 306 children were enrolled.Parents of 24 children refused to participate. Informed consent from all parents along with verbal consent from all children older than 5years was taken prior to enrolment.We measured their weight, height (in $>2$ years old) and length $(<2$ years old). Weight (nearest $0.1 \mathrm{~kg}$ ) was measured once at enrolment. Height (nearest $0.1 \mathrm{~cm}$ ) was measured using astadiometer. For children less than 2 years of age their supine length was measured using an infantometer. Chest circumference was measured at the level of nipples.

Ultrasonography was conducted using an HD7, high-end color Doppler machine (Philips Healthcare, India; subsidiary to Royal Philips, Netherlands) with three transducers, including curvilinear 3.5-5 MHz, linear 7-11 MHz, and transvaginal 5-7 $\mathrm{MHz}$. The machine offered both continuous wave (CW) and pulsed wave (PW) options for ultrasonography. All ultrasonography was performed by the radiologist (MKG) and inter-observer error was avoided.Sonographic evaluation was conducted in supine position during quite respiration, one to three hours after the last meal. Portal vein diameter was measured in the right hypochondrium below the tip of the $9^{\text {th }}$ costal cartilage at the level where the hepatic vein emerges from the inferior venacava. Care was taken not to compress the portal vein with excess pressure during examination. No preparation or sedation was required.

Statistical analysis was performed using SPSS v13.0.Results are presented as mean \pm standard deviation (SD) or median withrange, wherever appropriate. Demographic and anthropometric data were converted to categorical variables for statistical analysis. Categorical variables were compared by Man-Whitney test. Spearman's rank test was used to assess correlations between continuous variables like radiological, demographicand anthropometric variables. Estimates of correlation were expressed as correlation co-efficient (Spearman's rho). $\mathrm{R}^{2}$ was also calculated for each correlation. Scatter-plotswere used to depict these correlations. Logistic regression was performed to elucidate the predictors of portal vein diameter. The backward stepwise method was used. Age, height/length, and weight were assessed as independent continuous variables, while gender was taken as an independent categorical parameter. Adjusted R-squared values, standard errors (SE), coefficient of regression (â), p values and 95\% confidence intervals (CI) with upper and lower bounds were reported for each independent variable, in each model. Only significant independent variables have been presented.A $p$ value $<0.05$ was considered significant.

\section{Results}

A total 306 healthy children out of 330 were included in this study. Parents of 24 children refused to participate. These 306 children comprised of $138(45 \%)$ girls and $168(55 \%)$ boys.Subjects were stratified into different age groups. The number of children in each age group ranged from 19 to 38 . The highest $(n=38 ; 12.4 \%)$ and lowest $(n=19 ; 6.2 \%)$ number of 
children were in the age groups $96-119$ months and 72-95 months, respectively (Table 1). Majority (36.2\%) of the children weighed $<10 \mathrm{~kg}$ and only three children were $>40 \mathrm{~kg}$ (Table 2). A large proportion (39.2\%) of children was $<80 \mathrm{~cm}$ in heightwith only $7.5 \%>140 \mathrm{~cm}$ tall (Table 3). Table 4 summarizes the chest circumference measurements ofthe children.

Tables 5 \& 6 show portal vein diameter measurements in relation to age and gender. It is evident from the tables that though the portal vein diameter is increasing with age but for the same age group there is no significant difference between boys and girls (Figures $1 \& 2$ ). Tables $7 \& 8$ show that portal vein diameter increases with height/length. But for the same age group the values show no significant differencebetween boys and girls (Figures $3 \&$ 4). Similarly like age and height, the portal vein diameter is directly proportionalto weight). But for the same weight there is no significant difference between the boys and girls (Tables $9 \boldsymbol{\&} \mathbf{1 0}$ ). Portal vein diameter is proportionate to chest circumference, but no significant difference was observed between boys and girls (Tables 11 \& 12). Table13 shows that the portal vein diameter is positively correlated with independent variables like age, height/length, weightand chest circumference with significant $\mathrm{p}$ values. Thelogistic regression model (adjusted R-square: 0.922) elucidated age, height/length, weight and chest circumference as significant determinants of portal vein diameter (Table 14).

Table 1: Age distribution of study population

\begin{tabular}{lllc}
\hline Age (months) & Girls & Boys & Total \\
\hline$<1$ & 8 & 14 & 22 \\
$1-3$ & 11 & 15 & 26 \\
$3-6$ & 11 & 15 & 26 \\
$6-11.9$ & 14 & 20 & 34 \\
$12-23$ & 14 & 18 & 32 \\
$24-47$ & 17 & 20 & 37 \\
$48-71$ & 19 & 16 & 35 \\
$72-95$ & 8 & 11 & 19 \\
$96-119$ & 17 & 21 & 38 \\
$120-144$ & 19 & 18 & 37 \\
\hline Total & $\mathbf{1 3 8}$ & $\mathbf{1 6 8}$ & $\mathbf{3 0 6}$ \\
\hline
\end{tabular}

Table 2: Body weight distribution of children enrolled in the study

\begin{tabular}{llll}
\hline Body weight (kg) & Girls (\%) & Boys (\%) & Total (\%) \\
\hline$<10$ & $48(15.6)$ & $63(20.6)$ & $111(36.2)$ \\
$10-20$ & $50(16.3)$ & $59(19.3)$ & $109(35.6)$ \\
$20-30$ & $19(6.3)$ & $24(7.8)$ & $43(14.1)$ \\
$30-40$ & $21(6.8)$ & $22(7.3)$ & $43(14.1)$ \\
$>40$ & $2(0.006)$ & $1(0.003)$ & $3(0.009)$ \\
\hline Total & $\mathbf{1 3 8 ( 4 5 )}$ & $\mathbf{1 6 8 ( 5 5 )}$ & $\mathbf{3 0 6}(\mathbf{1 0 0})$ \\
\hline
\end{tabular}

Table 3: Height/length distribution of children enrolled in the study

\begin{tabular}{llll}
\hline Height/length $\mathbf{( c m )}$ & Girls (\%) & Boys (\%) & Total (\%) \\
\hline$<80$ & $51(16.7)$ & $69(22.5)$ & $120(39.2)$ \\
$80-100$ & $27(8.8)$ & $29(9.5)$ & $56(18.3)$ \\
$100-120$ & $26(8.5)$ & $35(11.4)$ & $61(19.9)$ \\
$120-140$ & $22(7.2)$ & $24(7.8)$ & $46(15)$ \\
$>140$ & $12(3.9)$ & $11(3.6)$ & $23(7.5)$ \\
\hline Total & $\mathbf{1 3 8 ( 4 5 )}$ & $\mathbf{1 6 8}(\mathbf{5 5})$ & $\mathbf{3 0 6 ( 1 0 0 )}$ \\
\hline
\end{tabular}

Table 4: Chest circumference distribution of children enrolled in the study

\begin{tabular}{llll}
\hline Chest circumference $(\mathbf{c m})$ & Girls (\%) & Boys (\%) & Total $(\%)$ \\
\hline $30-40$ & $27(8.8)$ & $37(12.2)$ & $64(21)$ \\
$40-50$ & $56(18.3)$ & $71(23.2)$ & $127(41.5)$ \\
$50-60$ & $47(15.3)$ & $54(17.7)$ & $101(33)$ \\
$>60$ & $8(2.6)$ & $6(1.9)$ & $14(4.5)$ \\
\hline Total & $\mathbf{1 3 8 ( 4 5 )}$ & $\mathbf{1 6 8}(\mathbf{5 5})$ & $\mathbf{3 0 6}(\mathbf{1 0 0})$ \\
\hline
\end{tabular}

Table 5: Portal vein diameter in relation to age and gender

\begin{tabular}{llll}
\hline & \multicolumn{3}{c}{ Mean portal vein diameter $(\mathbf{m m})$} \\
Age & Mean \pm SD & Girls & Boys \\
(months) & (months) & & \\
\hline$\leq 1$ & $3.35 \pm 0.42$ & $3.48 \pm 0.46$ & $3.29 \pm 0.40$ \\
$1-3$ & $3.85 \pm 0.44$ & $3.83 \pm 0.40$ & $3.87 \pm 0.48$ \\
$3-6$ & $4.08 \pm 0.51$ & $4.09 \pm 0.51$ & $4.08 \pm 0.53$ \\
$6-11.9$ & $4.34 \pm 0.73$ & $4.21 \pm 0.50$ & $4.43 \pm 0.85$ \\
$12-23$ & $4.75 \pm 0.68$ & $4.65 \pm 0.68$ & $4.82 \pm 0.68$ \\
$24-47$ & $5.19 \pm 0.83$ & $5.21 \pm 0.87$ & $5.18 \pm 0.82$ \\
$48-71$ & $5.95 \pm 0.82$ & $5.99 \pm 0.78$ & $5.89 \pm 0.89$ \\
$72-95$ & $6.03 \pm 0.73$ & $5.98 \pm 0.76$ & $6.07 \pm 0.74$ \\
$96-119$ & $7.22 \pm 0.45$ & $7.22 \pm 0.50$ & $7.21 \pm 0.42$ \\
$120-144$ & $7.67 \pm 0.68$ & $7.63 \pm 0.63$ & $7.72 \pm 0.75$ \\
\hline
\end{tabular}

Table 6: Range of portal vein diameter in relation to age portal vein diameter $(\mathbf{m m})$

\begin{tabular}{lccccc}
\hline $\begin{array}{l}\text { Age } \\
\text { (months) }\end{array}$ & Mean & Standard & $\begin{array}{c}\text { Median } \\
\text { deviation }\end{array}$ & $\begin{array}{c}\mathbf{5}^{\text {th }} \\
\text { percentile }\end{array}$ & $\begin{array}{c}\mathbf{9 5}^{\text {th }} \\
\text { percentile }\end{array}$ \\
\hline d"1 & 3.35 & 0.42 & 3.40 & 2.80 & 4.10 \\
$1-3$ & 3.85 & 0.44 & 3.85 & 3.10 & 4.60 \\
$3-6$ & 4.08 & 0.51 & 4.20 & 3.40 & 4.90 \\
$6-11.9$ & 4.34 & 0.73 & 4.10 & 3.60 & 7.40 \\
$12-23$ & 4.75 & 0.68 & 4.75 & 3.70 & 5.80 \\
$24-47$ & 5.19 & 0.83 & 5.00 & 4.00 & 6.60 \\
$48-71$ & 5.95 & 0.82 & 6.00 & 4.40 & 7.00 \\
$72-95$ & 6.03 & 0.73 & 6.10 & 5.00 & 7.10 \\
$96-119$ & 7.22 & 0.45 & 7.30 & 6.30 & 8.10 \\
$120-144$ & 7.67 & 0.68 & 7.70 & 6.50 & 9.00 \\
\hline
\end{tabular}

However, height/length emerged as the most consistent determinant (coefficient of regression: $1.536 ; \mathrm{p}<0.001 ; 95 \% \mathrm{CI}$ : $0.066-0.092)$. 


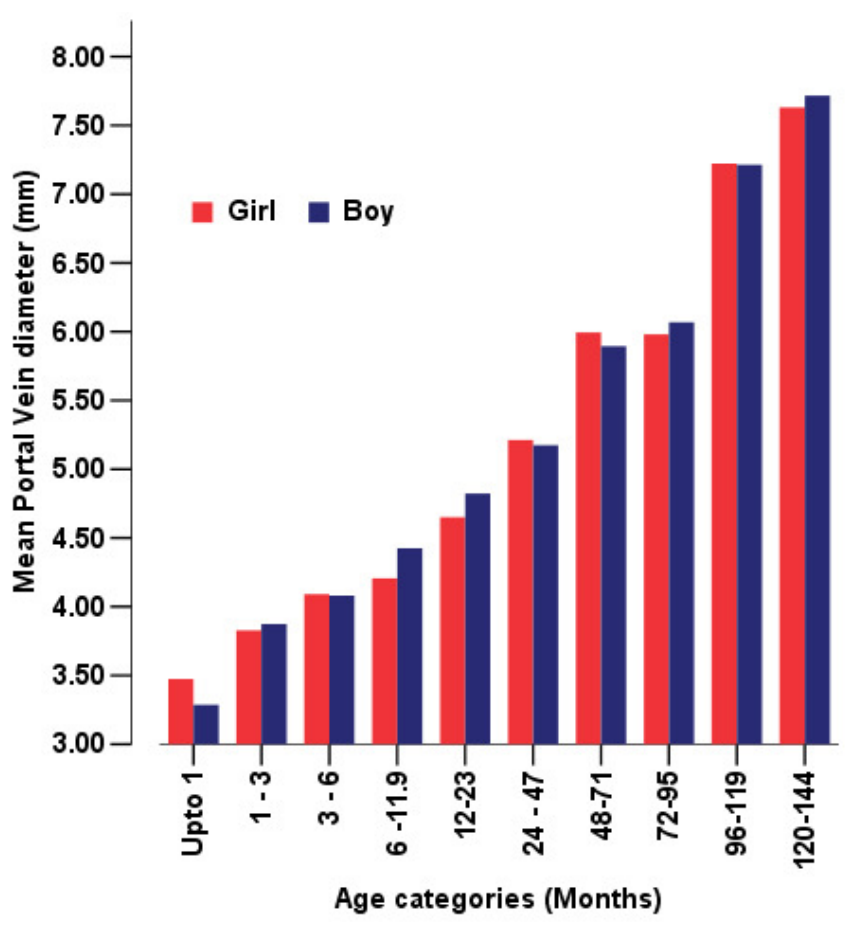

Figure 1: Portal vein diameter in relation to age and gender

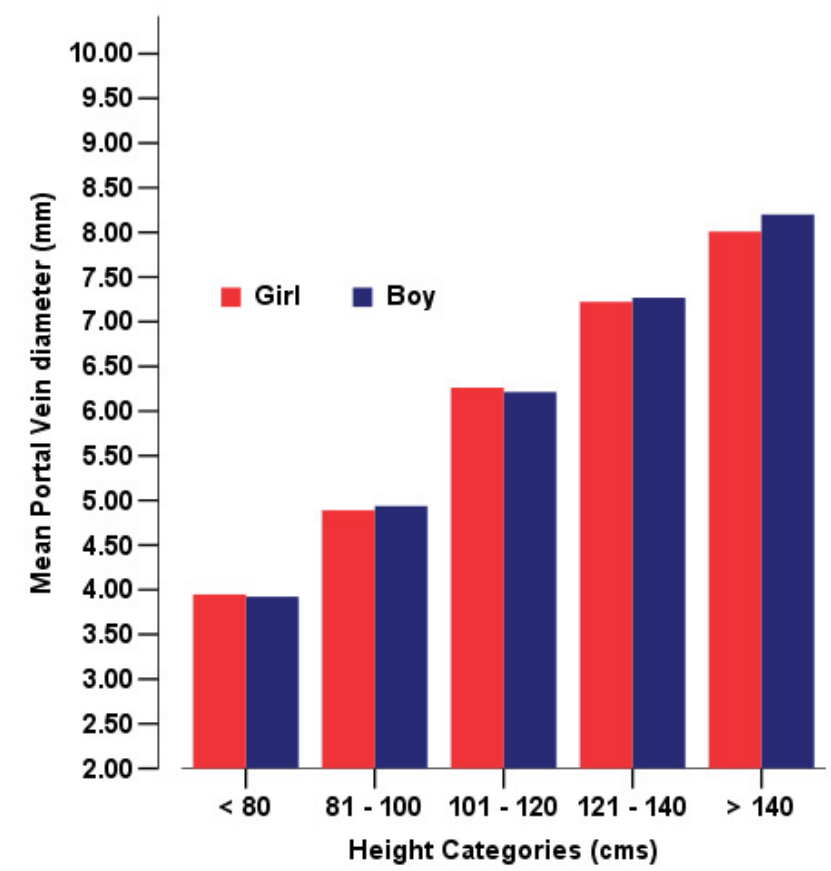

Figure 2: Portal vein diameter in relation to height/length and gender

Table 7: Portal vein diameter in relation to height/length and gender

\begin{tabular}{llll}
\hline & \multicolumn{3}{c}{ Mean portal vein diameter $(\mathbf{m m})$} \\
Height/length $(\mathbf{c m})$ & Mean \pm SD & Girls & Boys \\
\hline$<80$ & $3.93 \pm 0.55$ & $3.95 \pm 0.51$ & $3.92 \pm 0.57$ \\
$80-100$ & $4.91 \pm 0.53$ & $4.89 \pm 0.52$ & $4.94 \pm 0.54$ \\
$100-120$ & $6.23 \pm 0.61$ & $6.26 \pm 0.58$ & $6.21 \pm 0.65$ \\
$120-140$ & $7.25 \pm 0.38$ & $7.22 \pm 0.41$ & $7.27 \pm 0.36$ \\
$>140$ & $8.10 \pm 0.45$ & $8.01 \pm 0.42$ & $8.20 \pm 0.48$ \\
\hline
\end{tabular}

Table 8: The range of portal vein diameter in relation to height/length

\begin{tabular}{|c|c|c|c|c|c|}
\hline \multirow[b]{2}{*}{$\begin{array}{l}\text { Height / } \\
\text { length (cm) }\end{array}$} & \multirow[b]{2}{*}{ Mean } & \multicolumn{4}{|c|}{ Portal Vein diameter (mm) } \\
\hline & & $\begin{array}{l}\text { Standard } \\
\text { deviation }\end{array}$ & Median & $\begin{array}{c}5^{\text {th }} \\
\text { percentile }\end{array}$ & $\begin{array}{c}9^{\text {th }} \\
\text { percentile }\end{array}$ \\
\hline$<80$ & 3.93 & 0.55 & 3.90 & 2.80 & 5.00 \\
\hline $81-100$ & 4.91 & 0.53 & 4.80 & 4.00 & 5.80 \\
\hline $101-120$ & 6.23 & 0.61 & 6.45 & 4.60 & 7.10 \\
\hline $121-140$ & 7.25 & 0.38 & 7.30 & 6.50 & 8.10 \\
\hline$>140$ & 8.10 & 0.45 & 7.90 & 7.30 & 9.00 \\
\hline
\end{tabular}

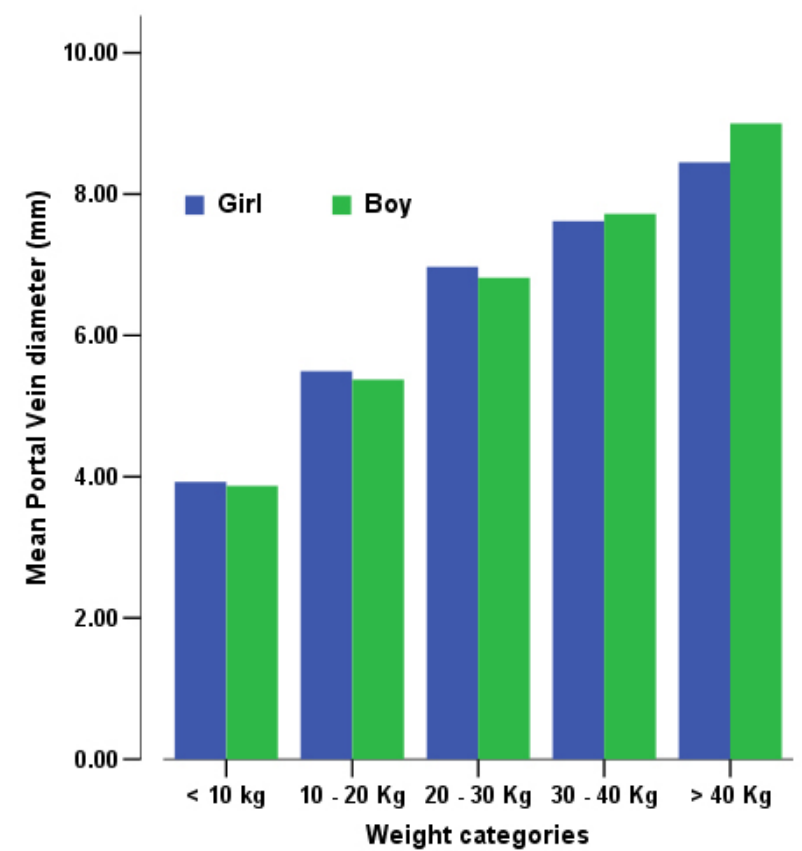

Figure 3: Portal vein diameter in relation to weight and gender

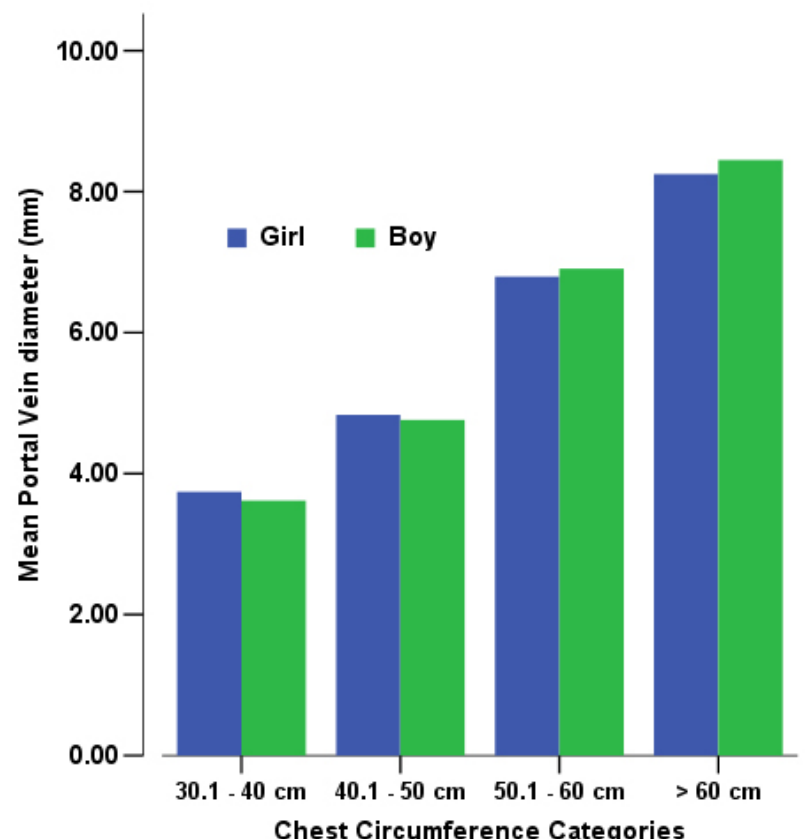

Figure 4: Portal vein diameter in relation to chest circumference and gender 
Table 9: Portal vein diameter in relation to weight and gender

\begin{tabular}{llll}
\hline & \multicolumn{3}{c}{ Portal vein diameter $(\mathbf{m m})$} \\
Weight $(\mathbf{k g})$ & Mean \pm SD & Girls & Boys \\
\hline$<10$ & $3.89 \pm 0.50$ & $3.93 \pm 0.48$ & $3.87 \pm 0.52$ \\
$10-20$ & $5.43 \pm 0.80$ & $5.49 \pm 0.83$ & $5.37 \pm 0.78$ \\
$20-30$ & $6.89 \pm 0.73$ & $6.97 \pm 0.46$ & $6.82 \pm 0.90$ \\
$30-40$ & $7.67 \pm 0.57$ & $7.62 \pm 0.57$ & $7.72 \pm 0.58$ \\
$>40$ & $8.63 \pm 0.32$ & $8.45 \pm 0.07$ & $9.00 \pm 0$ \\
\hline
\end{tabular}

Table10: Range of portal vein diameter in relation to weight

\begin{tabular}{|c|c|c|c|c|c|}
\hline \multirow{2}{*}{\multicolumn{2}{|c|}{ Weight (kg) Mean }} & \multicolumn{4}{|c|}{ Portal vein diameter $(\mathrm{mm})$} \\
\hline & & \multirow{2}{*}{$\begin{array}{l}\text { Standard } \\
\text { deviation }\end{array}$} & \multirow[t]{2}{*}{ Median } & \multirow{2}{*}{$\begin{array}{c}5^{\text {th }} \\
\text { percent }\end{array}$} & \multirow{2}{*}{$\begin{array}{l}95^{\text {th }} \\
\text { rcentile }\end{array}$} \\
\hline & & & & & \\
\hline$\overline{<10}$ & 3.89 & 0.50 & 3.90 & 2.80 & 4.90 \\
\hline $10-20$ & 5.43 & 0.80 & 5.30 & 4.00 & 6.90 \\
\hline $20-30$ & 6.89 & 0.73 & 7.00 & 2.90 & 7.60 \\
\hline $30-40$ & 7.67 & 0.57 & 7.70 & 6.50 & 8.80 \\
\hline$>40$ & 8.63 & 0.32 & 8.50 & 8.40 & 9.00 \\
\hline
\end{tabular}

Table 11: Portal vein diameter in relation to chest circumference and gender

\begin{tabular}{llll}
\hline & \multicolumn{3}{c}{ Portal vein diameter (mm) } \\
$\begin{array}{l}\text { Chest } \\
\text { circumference }(\mathbf{c m})\end{array}$ & Mean \pm SD & Girls & Boys \\
\hline $30-40$ & $3.67 \pm 0.48$ & $3.74 \pm 0.45$ & $3.62 \pm 0.50$ \\
$40-50$ & $4.79 \pm 0.77$ & $4.83 \pm 0.84$ & $4.76 \pm 0.72$ \\
$50-60$ & $6.85 \pm 0.72$ & $6.79 \pm 0.73$ & $6.91 \pm 0.71$ \\
$>60$ & $8.34 \pm 0.41$ & $8.25 \pm 0.24$ & $8.45 \pm 0.56$ \\
\hline
\end{tabular}

Table 12: Range of portal vein diameter in relation to chest circumference

Portal vein diameter (mm)

Chest circum- Mean Standard Median Minimum Maximum

ference $(\mathbf{c m}) \quad$ deviation

\begin{tabular}{llllll}
\hline $30.1-40$ & 3.67 & 0.48 & 3.60 & 2.80 & 4.70 \\
$40.1-50$ & 4.79 & 0.77 & 4.70 & 3.60 & 6.70 \\
$50.1-60$ & 6.85 & 0.72 & 6.90 & 5.00 & 8.10 \\
$>60$ & 8.34 & 0.41 & 8.40 & 7.40 & 9.00 \\
\hline
\end{tabular}

Table 13: Correlation of portal vein diameter with different demographic and anthropometric parameters

\begin{tabular}{lll}
\hline Variable & Correlation statistics & $\begin{array}{l}\text { Portal vein } \\
\text { diameter } \\
(\mathbf{m m})\end{array}$ \\
\hline Age (months) & Correlation coefficient $(\hat{\mathrm{a}})$ & 0.927 \\
& $\mathrm{p}$ value & $<0.0001$ \\
Height/length $(\mathrm{cm})$ & Correlation coefficient $(\hat{\mathrm{a}})$ & 0.952 \\
& $\mathrm{p}$ value & $<0.0001$ \\
Weight $(\mathrm{kg})$ & Correlation coefficient $(\hat{\mathrm{a}})$ & 0.933 \\
& p value & $<0.0001$ \\
Chest circumference & Correlation coefficient $(\hat{\mathrm{a}})$ & 0.938 \\
$(\mathrm{~cm})$ & $\mathrm{p}$ value & $<0.0001$ \\
\hline
\end{tabular}

chest circumference.The portal vein diameter increases with the independent variables highlighted in this study, irrespective of gender.Both boys and girls were comparable in terms of demographic, anthropometric and ultrasonographic variables. The diameter of portal vein increases with the age, weight, height/length and chest circumference of the child with similar correlation in both genders.Body height/length is a better indicator for determining cut-off values for portal vein diameter than age. It has been found that the normal diameter of portal vein can be predicted with high confidence in relation to body height and age.

The portal vein diameteris better established in adults. It has been examined in several studies and portal vein dimensions are slightly larger in men. ${ }^{11-13}$ Similar studies in children arelimited. No study has been conducted in India to establish the normal portal vein diameter in children and its variation according to demographic and anthropometric profile.Shankar et al ${ }^{14}$ fromRaichur, India conducted a study in adultsto determine the normal range of portal vein diameter. Ours is the first study from India to elucidate normal portal vein dimensions in children with respect to their anthropometric

Table 14: Logistic regression model for predicting portal vein diameter

\begin{tabular}{lllllcr}
\hline \multirow{2}{*}{ Determinant } & \multicolumn{4}{c}{ Regression model estimates } \\
\cline { 2 - 7 } & $\begin{array}{l}\text { Adjusted } \\
\text { R-square }\end{array}$ & $\begin{array}{l}\text { Standard } \\
\text { error }(\mathbf{S E})\end{array}$ & $\begin{array}{l}\text { Coefficient of } \\
\text { regression }(\mathbf{a})\end{array}$ & P value & \multicolumn{2}{c}{$\begin{array}{c}\text { 95\% confidence intervals } \\
\text { (Upper bound - lower bound) }\end{array}$} \\
\hline Age & 0.922 & 0.003 & -0.247 & 0.002 & -0.013 & -0.003 \\
Height/length & 0.922 & 0.007 & 1.536 & $<0.0001$ & 0.066 & 0.092 \\
Weight & 0.922 & 0.011 & 0.181 & 0.011 & 0.006 & 0.048 \\
Chest circumference & 0.922 & 0.017 & -0.526 & $<0.0001$ & -0.134 & -0.066 \\
\hline
\end{tabular}

\section{Discussion}

Our results provide an ultrasonographic standard set of normal values of portal vein diameter in children according to age, gender and anthropometric parameters like weight, height and and demographic characteristics. Patriquinet $\mathrm{al}^{11}$ studied156 childrenaged $<1$ to 16 years and found that the caliber of portal vein steadily increases with age, weight and height of the child. They alsoreported a slight difference between boys and girls. Our results are comparable though we did not notice any 
difference across gender. Soyupakaet $\mathrm{al}^{15}$ examined 167 children including 91 males and 76 females, aged from $<1$ to 15 years. They demonstrated that the diameterof the portal vein increases with the age, weight, height, and BMIof the child, with no significant variations between boys and girls. They concluded that both age and height correlate well with the portal vein diameter.Our data demonstrates strong correlation between portal vein diameter and age, height, weight and chest circumference, with height showing the strongest correlation.

Our study has certain limitations.Since the study was conducted in West Bengal, our results may not be representativeof the entire Indian population. We did not account for the socioeconomic and religion profile of our study population. Our study enrolled only 306 children, and a larger study spread across different states of India can help better validate our results.

In summary, Portal vein diameter in children increases with age and anthropometric parameters with no difference between both genders. However, a larger study is recommended to validate our results. With further studies it would also be desirable to construct a normal portal vein diameter curve for children, so as to facilitate the diagnosis of portal hypertension in children.

\section{Acknowledgements}

The authors acknowledge Dr. AsokDatta, Head, Department of Pediatrics, for guiding us with the research design.

\section{References}

1. Child GC, editor.Portal hypertension as seen by 17 authorities.
Philadelphia: WB Saunders Company; 1974.p.102-20.

2. Webb LJ, Berger LA, Sherlock S. Grey-scale ultrasonography of portal vein. Lancet. 1977;2:675-7.

3. Meire EB, Dewbury KC, Cosgrove DO, editors. Abdominal and general ultrasound. Edinburgh: Churchill Livingstone; 1993.p.1-311.

4. Cook GC.Tropical gastroenterology. New York: Oxford University Press; 1980.p.150-6.

5. Merritt CR. Ultrasonographic demonstration of portal vein thrombosis. Radiology. 1979;133:425-7.

6. Juttner HU, Jenney JM, Ralls PW, Goldstein LI, Reynolds TB. Ultrasound demonstration of portosystemic collaterals in cirrhosis and portal hypertension. Radiology. 1982;142:459-63.

7. Weinreb J, Kumari S, Phillips G, Pochaczevsky R. Portal vein measurements by real-time sonography. AJR Am J Roentgenol. 1982;139:497-9.

8. Nestaiko OV, Iarovoi AV, Bekov AD. [Ultrasonographic symptoms of portal hypertension]. Med Radiol (Mosk). 1991;36:4-6.

9. Subramanyam BR, Balthazar EJ, Madamba MR, Raghavendra BN, Horii SC, Lefleur RS. Sonography of portosystemic venous collaterals in portal hypertension. Radiology. 1983;146:161-6.

10. Weltin G, Taylor KJ, Carter AR, Taylor CR. Duplex Doppler: identification of cavernous transformation of the portal vein. AJR Am J Roentgenol. 1985;144:999-1001.

11. Patriquin HB, Perreault G, Grignon A, Boisvert J, Filiatrault D, Garel L, et al. Normal portal venous diameter in children. Pediatr Radiol. 1990;20:451-3.

12. Vocke AK, Kardorff R, Ehrich JH. Sonographic measurements of the portal vein and its intrahepatic branches in children. Eur $J$ Ultrasound. 1998;7:121-7.

13. Corness JA, McHugh K, Roebuck DJ, Taylor AM. The portal vein in children: radiological review of congenital anomalies and acquired abnormalities. Pediatr Radiol. 2006;36:87-96.

14. Shetty RSS, Kulkarni R. Estimation of portal vein diameter in co-relation with the age, sex and height of an individual. Anatomica Karnataka. 2011;5:13-6.

15. Soyupak S, Gunesli A, Seydaoglu G, Binokay F, Celiktas M, Inal M. Portal venous diameter in children: normal limits according to age, weight and height. Eur J Radiol. 2010;75:245-7. 